\title{
Modular Stories: An Examination of Multi-Modal Transtexts in Relation to The Modular Body
}

James Dalby ${ }^{*}$

DOI: https://doi.org/10.17230/9789587206289ch6

Jenkins begins his essay "Transmedia Logics and Locations" (2017) by reminding us that Transmedia is an adjective, and not a noun. "Transmedia needs to modify something", he writes (2017, p. 220). While there may be arguments to suggest that Transmedia isn't necessarily always an adjective -at all times and in all ways-in principle, this paper will proceed from the underlying contention suggested by Jenkins that Transmedia is a process, a "relationship between multiple media platforms and practices" that can facilitate the modification of a text from one state to another. Based on this premise, the aim is to demonstrate that Transmedia has the capacity to offer new questions and perspectives on current conceptions, specially related to the manner in which contemporary media texts work as pieces of communication. This paper will argue that Transmedia texts are necessarily dissimilar to media "artefacts", and as a consequence, require new concepts and approaches lexica, as existing theoretical principles may not effectively apply. As a possible outcome we may be able to use Transmedia texts as new lenses to view narrative concepts that may have been previously the preserve of theory alone.

In his recent paper regarding additive comprehension and Transmedia storytelling, Delwiche (2017) bemoans the fact that to date, in his view, there are only a few precious examples of the "origami unicorn" within Transmedia narratives, discussed by Jenkins (2006), among others, in relation to the concept of "additive comprehension". This somewhat abstract term refers to an origami unicorn prop featured in the director's cut version of the movie Blade Runner (Scott, 1982), where the inference that the main character, Deckard, is actually one of the Replicant humans that he is tasked to hunt-down (an aspect not present in the original cinematic release) adds a new layer to the overall understanding and

Bachelor of Arts in Philosophy with History, University of Hertfordshire, England; Master's Degree, Post Graduate Certificate of Higher Education at University of Gloucestershire, England. Senior Lecturer in Media Production at University of Gloucestershire. Email: jdalby@glos.ac.uk 
development of the narrative. Such is the shift in audience comprehension of the Blade Runner story, provided by this single detail, that it produces an entirely alternative experience to the original cinematic release, and as a consequence, it may be appropriate to approach the various versions of the film (including 'The Final Cut' version) as texts fundamentally separate from each other. They are, in effect, entirely different narratives.

This notion is suggested by Flisfeder (2017, p. 97) when he observes that "Blade Runner is inherently a product of post-modernity, a constant simulacrum of itself. It is impossible to say that any one version is more authentic than the others; it is also difficult to say which one is truly the "original". It is important to note that the modification we are concerned with is not the one that involves what is called the fundamental structural changes to the text, in the sense of alternative endings or the introduction of key new narrative events (which could reasonably be expected to produce entirely separate experiences), but that of the subtext and inference, of implication and context. If we accept its capacity to create versions of a core text with separate identities, there may be significant implications for our discussion of multi-modality in Transtexts, as we shall see below.

Delwiche argues that as an excellent example of additive comprehension -where the introduction of a single new detail within a narrative can fundamentally alter its entire understanding by the audienceBladerunner's "origami unicorn" has yet to find its equal within Transmedia narratives. This arrives as a surprise and a disappointment, given that the nature of Transmedia storytelling ought to lend itself well to the introduction of potentially narrative-altering story elements. After positing several useful definitions of different Transmedia narrative types as Soft Transmedia, Hard Transmedia, Decorative Transmedia and Alternate Reality $G a$ mes (2017, p. 37), he concludes that perhaps the reason for this perceived deficiency within Transmedia narratives is the lack of multimodal literacy within Transmedia audiences. Also, he considers there is an underlying and incorrect assumption among the Transmedia community that audiences are as engaged and desirous of seeking out trans-platform content as we might wish; a problem, he writes, of "technological determinism".

This position is persuasive, and indeed it might be argued that even recent Transtexts, such as the excellent Pa: Vs. Stuff (Regan, 2016) YouTube experience -which includes a number of story-altering elements intro- 
duced in separate narrative spaces (although admittedly all contained on YouTube)-, may not have produced defining additive comprehension moments compared to the "origami unicorn" model. These moments arise when the whole narrative, and by extension the whole audience experience, is turned on its head by the introduction of a new subtextual story element. However, while Delwiche may be correct, he may also have established some potentially "narrow limits" to work within, and as such, it may be instructive to consider two particular premises when examining his conclusions: that of authorship, and Jenkins' earlier reminder that Transmedia is an "adjective".

Each of Delwiche's four Transmedia examples appears to deal exclusively with "authored" Transmedia experiences, and consequently, with "canonical" content with little or no inclusion of User Generated Content (UGC), or "fanon" texts. If we accept the adjective definition of Transmedia suggested earlier, then we may need to extend Delwiche's boundaries to include such content if we wish to fully explore the relationship between Transmedia and "additive comprehension". In addition, we could argue that UGC is a fundamental part between this process and the relationship of "Transmediation", and to exclude such content makes only part of the "whole" visible, that is Transmedia storytelling.

This, in itself, may appear as a somewhat limited investigation; the "origami unicorn" concept being a relatively obscure and perhaps unique circumstance of additive comprehension. However, what we are concerned with in this paper is to emphasise the unique nature of Transmedia narratives; we may visualize Transmedia's offer, in relation to established narrative communication notions, by illustrating how principles such as additive comprehension and the "origami unicorn" concept function differently in a Transmedia environment. In the first instance, it is necessary to examine what appears to be one of the most fundamental aspects that distinguishes Transmedia from almost all others.

In an earlier work presented at the 2016 International Conference on Communication, Media, Technology \& Design, on Immersion and Suspension-of-Disbelief in Transmedia, I attempted to prove that Transmedia stories were fundamentally different to traditional "artefactdefined" experiences -such as film, theatre and literature- by arguing that the immersion on a Transmedia text is an entirely different process and experience from that of a movie, play or novel. This is because 
(Holland, 1967) when we psychologically "suspend disbelief" to achieve immersion within a "traditional" fictional text, we normally seek to retain some emotional connection to it whilst "disengaging" the "planning-toact" function within our cognitive process. So that, for example, when the killer appears on-screen in the horror movie, we can experience fear without the overriding sense of personal threat that might cause us to flee the cinema! In order to do this, Holland argues, we must recognise the story as artificial by "framing" it away from reality, and accept it as such, in order to trust it.

My argument was that within a Transmedia narrative, the decisionmaking process normally involved in the Transmedia experience means that we cannot "disconnect" this "planning-to-act" process, partly because interaction requires action, and as a result, traditional suspension-ofdisbelief immersion is not possible. The difficulty arises from the need to "frame" a text away from reality. Within a Transmedia experience we effectively include the frame as a part of it, which continually reinforces the "unreality" of the text, preventing traditional suspension of disbelief, and consequently, immersion.

At first glance, this may appear to be an 'over-engineered' addition to this discussion; after all, we can easily illustrate that a movie and a Transmedia text are fundamentally different experiences, even down to their technological and conceptual premises. Nevertheless, this distinction is important because it illustrates the inherent difficulty, and potential impossibility, of introducing narrative theory from a format such as film -including concepts such as additive comprehension, similar to the Bladerunner "origami unicorn"- into Transmedia narratives. It is not so much that audiences lack motivation, or multimodal literacy, but that our expectations of the audience reactions to Transmedia story elements are possibly influenced by the ways they react to a movie, novel or play. This, it seems, could sound more like "technological determinism" rather than Delwiche's definition; the "origami unicorn" cannot work in the same way in a Transmedia narrative, because audiences are unable to "suspend disbelief" in the same way they would for a movie. Yet, despite of this, we still expect to see comparative results.

Maybe, instead of observing Transmedia texts with the same lens we might use for films, the key is to ascertain what makes Transmedia texts so very different by comparing the outcomes of a concept such as "additive 
comprehension" between both. One important consideration is that film, television, radio and literature are all examples of story artefacts, inasmuch as they can be argued to exist independently of an audience. This is not meant in the sense Nieztsche proposed, as a monological conception of the artistry of a film or play, nor does it seek to suggest that narrative concepts conveyed by a text (courage, love, etc.) can exist without an audience to decode them. It is simply a recognition of the physical relationship that audiences have with the delivery method of the text: a movie playing in an empty cinema is still -arguably- "the movie". When we refer to Blade Runner, for example, we refer to a self-contained media experience that has its own identity, hence the suggestion that the director's cut version is an entirely separate film to the original studio release; each has its own identity defined within its own limits.

We may have to broaden our definition to include theatre, as a play probably does not exist until brought to life by performers, but we might still be able to describe a traditional theatre experience as an "artefact" of sorts. I do so here, in order to emphasise the contrast with an alternative, "non-artefact" form of storytelling; ludic frameworks and game-play narratives, which cannot be described as "artefacts" because they cannot exist without their participants. As Brown (2012, p. 8) observes, "games need players, and this is one of the ways they are differentiated from the majority of other media experiences, which require only audiences".

In my earlier paper, I concluded that Transmedia narratives have far more in common with games than they do with movies, novels or plays, because Transmedia users are-by necessity- participants, rather than audiences, and as such, the way we immerse ourselves in Transmedia texts is the same as within gameplay; we immerse ourselves within the participatory space of the experience, and not the representational space as we do with films, theatre, etc. As an example, Salen \& Zimmerman (2004) quote Gorfinkel:

Immersion is not a property of a game or media text but is an effect that a text produces. What I mean is that immersion is an experience that happens between a game and its player, and is not something intrinsic to the aesthetics of the game. The confusion in this conversation has emerged because representational strategies are conflated with the effect of immersion. Immersion itself is not tied to a replication or mimesis of reality. For example, one can get immersed in Tetris. Therefore, immersion into game play seems at least as important as immersion into 
a game's representational space. It seems that these components need to be separated to do justice and better understand how immersion, as a category of experience and perception, works (as cited in Salen \& Zimmerman, 2004, p. 452).

What we may hopefully be able to conclude is that Transmedia experiences are not simply separate from all others in terms of technology, platform, practice or delivery system, in the way that film is separate from literature for example, but by having more in common with ludic narratives. Despite not always involving game-play, Transmedia texts are unique, and must be regarded as such in any analysis. It is not enough to transpose concepts from artefact-based narrative experiences into the Transmedia sphere, and expect to find equivalency. Instead, the way we think about the production of both Transmedia experiences, and those in which we analyse their uses and effects, requires new lexica of principles, technique, and even language, potentially separate from anything which has come before. This is necessarily restrictive in one sense, but also opens entirely new avenues for exploration in another.

For example, while we may agree with Delwiche that the "origami unicorn" standard of additive comprehension has not been achieved or equalled within Transmedia experiences in its original "movie" sense, if we include UGC and "fanon" content in our discussions, and especially if we accept Transmedia as an adjective, we may be able to ask new questions about the medium. Perhaps, additive comprehension, instead of referring to a narrative device, could potentially refer to something more abstract, or more fundamental. If the "origami unicorn" which alters the whole narrative experience is not simply something analytic, selfcontained and "authored", but instead something synthetic, fluid, and externally-generated beyond the original authorship of the text -arguably something that artefact-based media cannot achieve- then the capacity for "additive comprehension" increases immeasurably. We may even begin to see that Transmedia storytelling offers opportunities to examine the relationship between text and audience in a manner that might previously have been confined to the realm of "thought experiments". As a result, in the remainder of this paper I propose, via a specific case-study, that Transmedia storytelling can provide a circumstance where the "origami unicorn" in question is not a simple narrative device, but instead the actual reality of the text itself. 
The Modular Body (Kaayk, 2016) is an online, non-linear science fiction narrative experience, available primarily at www.themodularbody. com and also through various social media platforms such as Facebook and YouTube. Created by Dutch artist and filmmaker Floris Kaayk, the story covers the development of OSCAR, a bio-engineered organism developed from human cells, and composed of organic 'modules' which serve specific functions such as respiration and movement, and which can be rearranged and upgraded. With high-quality production values and convincing 'pseudoscience' based on existing and contemporary knowledge and technologies, the whole experience of The Modular Body has the feeling of something inherently plausible. The creators of the experience, though, openly acknowledge and confirm that The Modular Body is fictional, since they state that: "The Modular Body is an online science fiction story about the creation of OSCAR, a living organism built from human cells" as the opening sentence on the "About" section of the main website.

As a self-contained narrative experience within themodularbody.com, we may argue that The Modular Body is not, strictly speaking, a Transtext, inasmuch as the breadth of the experience exists in a single space online, and as such, takes the form of a deconstructed film rather than as a Transmedia experience per-se. The video artefacts that make up The Modular Body are hosted on YouTube, and the creators have also disseminated key videos via Facebook and other social media platforms. However, we might suggest that even this process may not produce a true Transmedia narrative, as we do not necessarily gain new experiences or a narrative understanding from story artefacts, specifically on separate platforms. It is highly possible that the dissemination of different "types" of videos found/viewed in separate online spaces, that contribute to the overall narrative experience -such as a "crowdfunding" video to raise money for the OSCAR project-could produce a transmediated relationship between texts, as suggested by Jenkins in his "adjective" statement mentioned before. Nonetheless, what is fascinating about The Modular Body in this discussion is not the text itself but the interaction and comments around the various video artefacts by the audiences, which, in turn, firmly position the experience as a Transtext. The extensive user interaction and comments tends to take two forms: content from those viewers who are aware that The Modular Body is a fictional narrative, and content from those who are unaware of that. 
A significant number of the users who have interacted with The Modular Body content, especially starting 2016, seemingly genuinely believed that they were engaged in a process of comment, sharing and interaction with a "real life" story event. The introductory video of OSCAR, published to Facebook on April 14th, 2016, has currently over 26,000 comments; the majority of those dating from April and May 2016 (more than two thirds) appear to be interacting with the text as a real-world artefact. Comment takes many forms, and we immediately see several broadly positive themes emerging, spanning excitement and optimism, support and defence of the project and scientific curiosity:

I am vascilating (sic) between, fascination and horror within the context of pure wonderment. Extraordinary (Zia Wesley, $15^{\text {th }}$ April, 2016). For all you closed minded idiots making comments, Oscar is a collection of organs, limbs, and tissue which was created to prove that they can build replacement parts for humans. It's actually very amazing. People who need heart transplants won't have to wait for a donor to die in order to get a new heart. This is huge! (Rocco Oliverio, 16 $6^{\text {th }}$ April, 2016).

I have question. The meat is muscle. Muscle needs blood to stay moist and given its vitamins and nutrients. How will this "muscle" survive, not decay without blood circulation? Muscle without blood will die, decay (Alan Kenyon, 29 ${ }^{\text {th }}$ April, 2016).

You can clearly see the connections for each piece to get power from the "brain". How is this fake. It's just sending a electrical charge to organism and its twitching. Similar thing to putting salt on severed frog legs or salt on a dead octopus. It will move. Welcome to science people too bad nobody paid attention in school (James Lethcoe, $15^{\text {th }}$ April, 2016).

At the same time, the nature of the content of The Modular Body is at-once unsettling and controversial. The appearance of the organism OSCAR is somewhat challenging, as it moves in spasmodic twitches clearly designed to appear unpleasant, while the undeniably Frankensteinian storyline (clearly intended by the creators who reference Mary Shelley's Frankenstein on the "About" section) explores some of the ethical boundaries that such technology would ostensibly face, were it real. As such, many of the comments are less positive and explore moral, religious and economic objections, including arguments relating to intensive farming, vivisection and healthcare, while others contribute cynicism and posit that the footage may actually be fake: 
Something tells me we're screwing with things we should never even be trying... it's going to come back and bite us one of these days \# nothanks (Michelle French, 15 ${ }^{\text {th }}$ April, 2016).

I feel like this is crossing into the realm of morality. Why are you trying to make a human prototype? Besides the fact that it's wrong, has anybody seen Terminator 2 judgement day? Hello, stop trying to make artificial intelligence more advanced than it already is for the love of God (Ronnie Rhodes, $15^{\text {th }}$ April, 2016).

What's the purpose of this... how will this benefit man kind? I can't think of anything... This is what happens when you throw god out the picture. Science is creating monsters (Kelvin Lyrikel Laurent, 15 ${ }^{\text {th }}$ April, 2016). Lol reading the comments and everyone is like "this is scary" "humanity's gone wrong", etc... and all I can think is that it's not nearly as terrifying as footage from factory farms, or what we do to humans and other animals on a daily basis on this planet. If we are worried about losing our humanity, I would say don't worry. That ship sailed a long long time ago (Deanne McKay, 15 ${ }^{\text {th }}$ April, 2016).

Am I the only person looking at this logically and realizing that this could very simply be all electronic moving parts with just a fleshy or at least fleshy looking material around the mechanical parts? Plugging them into each other making the thing functional and moving? It's not a cyborg lol, it's not an organic being ran by electricity, it's just a robot with poultry all bound to it (Colin Michael, 15 ${ }^{\text {th }}$ April, 2016).

The wealth of comment generated in response to the video mentioned above and others displayed on a variety of platforms, such as YouTube and Buzzfeed, forms a fascinating extension to the original narrative, and firmly 'Transmediates' The Modular Body experience. The creators were also able to capitalise on this by interacting with audiences through comment replies and links to other story artefacts. What is interesting here is that while the "tone-of-voice" of these replies is certainly "in character", comments from The Modular Body to users continue to openly refer to the experience as a "story" and provide direct links to themodularbody.com, where again the fictional nature of the experience is clearly acknowledged.

Thanks for the great Q\&A! \# projectoscar We're rounding up now. Don't forget to do the full experience the online science fiction story www.themodularbody.com (The Modular Body, 2016, April 17).

[In reply to Alan Kenyon, above]

Hi Alan, here you can see how the blood circulation is variable and how 
it works: https://www.youtube.com/watch?v=psV1LLQ_boQ The needed blood is donated by Cornelis Vlasman. Beside the YouTube channel of Cornelis Vlasman you can also have a look at www.themodularbody. com for explanation and to get full experience (the modular body, 2016, April 29).

It should be noted that the majority of the UGC under discussion emanates from the social media sphere of The Modular Body experience; by contrast, the equivalent introductory video hosted on YouTube on April $14^{\text {th }} 2016$ has only a little over 1,000 comments to-date, and very few of these suggest that the author believes the video to be "genuine". The likely explanation for this is that the creators have also uploaded behind-the-scenes and "making-of" videos to YouTube which directly link to the narrative content, illustrating -for example- how OSCAR was animated, adding yet another layer to the authors' acknowledgement of the text's fictional status.

This continued acknowledgement from the creators of The Modular Body that it is a fictional narrative is important to our discussion of additive comprehension within Transtexts. The notion of creating a plausible and convincing narrative, aimed at "misleading" an audience into believing that a story is "genuine", is well known. Movies such as The Blair Witch Project (1999), uTR advertising such as the Hi-Tec brand's Liquid Mountaineering (2010) campaign, and contemporary Transtexts such as PazVs. Stuff are just a small sample of texts that have effectively utilised and implemented this concept directly to great effect. The idea is not a modern one either; we might suggest that 'hoaxes' such as the Cottingley Fairies (1917) could be included in such a discussion, while Orson Welles' famous radio broadcast of War of the Worlds in 1938 offers an arguably more indirect and "tertiary" approach. Although what was said about broadcast listeners as "deceived" and running to the streets in fear has been proven false, the number of subsequent articles published and commentaries describe how audiences were "taken-in" and did, in fact, flee their homes -despite nothing of the kind actually taking place- is an interesting case-in-point. Audiences being "mislead" by a fictional narrative, thus, is a common occurrence; even though, The Modular Body offers a different, and perhaps somewhat unique instance of the phenomenon for two clear reasons: 
- At no point are the creators of the text seemingly intending to mislead their audience; The Modular Body openly acknowledges that it is a constructed narrative.

- As a result of the social media platforms involved, audiences can comment and interact with the text in a visible and accessible way, significantly contributing to the overall lexicon of The Modular Body experience, both by encouraging and influencing new users to read it as "real" through comments and shares, and also by providing extensive UGC to improve the reception and narrative of the overall experience.

Then, what we have is a self-contained and canonical fictional narrative intended as an entertainment experience with no ostensible attempt to "mislead" an audience into believing it is anything other than fictional. While at the same time, it is connected to an extended-narrative version of itself, which includes non-fictional content (real-world users commenting on what they perceive to be a real-world narrative) in an unusual dichotomy, where the "canon" is fictional, and the "fanon" (UGC) content is -arguably- "real-world" non-fiction.

The relationship between "canon" and "fanon" content is an ongoing and broadly-discussed concept, especially regarding the potential authenticity of fan-generated texts in relation to the authored source. In her work on "Fandom and Transtexts", Stein (2017) makes a compelling case for the relevance and contribution of fan-texts, arguing that Transtexts that include fan-generated content "[are] an ongoing, dynamic, creative process of collective authorship that spans commercial, independent, and fan-production" (2017, p. 72). Later, she adds that: "we could imagine the ever-expanding transtext with a small portion that is the official, "original" work, a kernel of inspiration, a jumping off point, so to speak" (2017, p. 73).

Despite the experience of The Modular Body certainly seeming to correspond to this definition -as a "jumping-off point" for an extended narrative-, again it is unusual because these are not "fans" connecting with, and extending, a constructed narrative in the traditional "fanon"/ UGC sense. If The Modular Body actually was "real" the comments from these users would, of course, be unchanged and, consequently, the lines of "authorship" and "authenticity" would potentially become blurred. 
Indeed, if by "authenticity" we allow ourselves to consider related concepts such as "genuineness", "validity", "originality", and "legitimacy", then the verisimilitude of the UGC might even lead to a suggestion that that body of content is perhaps more authentic than the original Modular Body text. It does, after all, provide an interesting real-world glimpse of what reactions to such technology would likely be, if it were to "exist" at some future time. Whether we take this view or not, the overall effect is that The Modular Body participant is provided with a fascinating series of narrative extensions to the original text, venturing into morality, politics, religion, human and animal rights, among others. At this point, it could be argued that the overall connected experience becomes an entirely separate story to the original narrative, in the manner of the various versions of Bladerunner discussed by Delwiche. The Modular Body experience now seemingly exists in three separate modes:

1 The original, self-contained, authored narrative; the "canonical" content;

2 The "real-world" comments and other UGC (including GIFs and artworks) separate to the original content; the unintended 'fanon' content;

3 The extended narrative experience combining modes 1 and 2, for those participants who are aware of the fictional nature of the canonical content, with the addition of content from real-world users.

While much of the content from audience members runs along the lines of what we might expect from users confronted with The Modular Body if it were real, nevertheless, in Mode 3, the direction of the narrative is not controlled by the authors of the text, and may therefore deviate somewhat from the aims and intentions of the original experience. Even leaving this aside, we may still be able to argue that the various modes point to an unusual and interesting example of additive comprehension -perhaps not commensurate with the original "origami unicorn", but still unique in its own right- which is the way in which it relates to our earlier discussion of immersion in Transmedia experiences. Traditional concepts such as additive comprehension cannot easily be transposed from "artefact" media into "participatory" media, because the way we immerse ourselves in each is so fundamentally different. Immersion in Transtexts must by necessity take the form of immersion into a participatory space, as 
it occurs with ludic narratives, which rely on players/participants, rather than the representational space required for immersion in 'artefact' media such as film and literature. The extended version of The Modular Body therefore provides an excellent example of this participatory immersion;

- In Mode 1, the text exists as a self-contained and authored narrative; traditional immersion is arguably not possible for this text as we cannot achieve suspension-of-disbelief, due to our inability to disconnect the "planning-to-act" aspect of the cognitive process, because of the participation required.

- In Mode 2, participants arguably do not 'suspend disbelief' as they believe the experience to be real.

- In Mode 3, the original authored text is enhanced by the addition of "real world" content; again audiences are not required to "suspend disbelief" because the enhanced content is effectively "real". Immersion is participatory; it takes place in the act of participation with other audience members of The Modular Body texts, and the knowing synthesis of the canonical and UGC content.

The outcome of this work is to suggest that the "origami unicorn" of additive comprehension is in this case twofold: on one hand, it relates to the authorship, reality, and potential authenticity of the narrative, and on the other, it is the capacity for immersion in a media experience that -arguably-cannot be immersive by itself. The enrichment of the original narrative by the extended UGC opens up a participatory immersion lacking from the authored source content.

There is also, of course, participant content that is knowingly commenting on a fictional narrative, much of it stating repeatedly that The Modular Body is fictional. As a result, the whole UGC experience for The Modular Body, across various platforms and comments-threads, provides an interesting and nuanced "organic" narrative. This narrative exists as an ongoing and detailed addition to the experience of The Modular Body, as well as a real-world glimpse of the likely reactions if such technology were to exist one day. In the particular case of the introductory Facebook video previously mentioned, comment has continued well into May 2017, with entirely new users discovering it and providing their own contribution to the UGC narrative, and with some users still perceiving the text as "genuine". 
However, it is worth noting that this paper has not intended to provide, or to function as a textual analysis of The Modular Body; such an undertaking would necessarily need to be extensive, as the artefacts posted on YouTube and Facebook containing comments threads are numerous (over 26,000 comments just for the introductory Facebook video mentioned above). Instead, the aim of this work has been to emphasise the unique nature of Transtexts as pieces of communication and as participant experiences, and to comment on the opportunities that Transmedia storytelling offers to investigate narrative and communicative processes in circumstances that were previously preserved for imaginary and thought-experiments.

There are numerous threads of enquiry, not examined on this paper, that are potentially offered by The Modular Body experience and other current similar texts, or ones that will come after. These might potentially include epistemological associations of participants interacting with the same core text and the narrative, that actually experience utterly separate sense-data based on their interpretation of the text as "genuine" or fictional. These could bring broader connotations of -and potential for- plurality in storytelling, allowing flexible narrative interpretations that offer a multiplicity of readings, interpretations and meanings. It is, of course, instructive to note that The Modular Body is in itself a modular narrative, and the story that is generated through the assemblage of its components is as Frankensteinian as OSCAR itself.

The advantage of any modular design is the flexibility that stems from the capacity of modular components to be upgraded and re-tasked, and the experience of The Modular Body demonstrates that this concept works as well with storytelling as anything else. As a consequence, The Modular Body provides us with a glimpse of the opportunities presented by Transmedia experiences -which, by definition above (Transmedia as an adjective) are necessarily of a form of modular construction- maybe for the ongoing development of narrative communication. 


\section{References}

Brown, D. W. (2012). The suspension of disbelief in video games (Doctoral thesis). Brunel University, London, UK. Retrieved from https://bit. ly/2CDQayn

Deeley, M., Fancher, H., Kelly, B., Powell, I., Perenchio, J., Scott, R., \& Prischman, P. (Producers), \& Scott, R. (Director). (1982). Blade Runner [Motion picture]. USA: Warner Bros. Pictures.

Delwiche, A. (2017). Still Searching for the Unicorn. Transmedia Storytelling and the Audience Question. In B. W. L Derhy Kurtz \& M. Bourdaa (Eds.), The Rise of Transtexts. Challenges and Opportunities (pp. 33-48). Abingdon, England: Routledge.

Flisfeder, M. (2017). Postmodern Theory and Blade Runner. London, England: Bloomsbury.

Holland, N. (1967). The 'Willing Suspension of Disbelief' Revisited. The Centennial Review, 11(1), 1-23. Retrieved from https://bit.ly/2VfEs10 Jenkins, H. (2006). Convergence Culture: Where Old and New Media Collide. New York, NY: New York University Press.

Jenkins, H. (2009, December 12). The Revenge of the Origami Unicorn: Seven Principles of Transmedia Storytelling (Well. Two Actually, Five More on Friday) [web log comment]. Retrieved from https://bit. ly/2tovyEm

Jenkins, H. (2017). Transmedia Logics and Locations. In B. W. L Derhy Kurtz \& M. Bourdaa (Eds.), The Rise of Transtexts. Challenges and Opportunities (pp. 220-240). Abingdon, England: Routledge.

Regan, S. (Director). (2016). Paz Vs. Stuff [YouTube channel Serie]. England, UK.

Salen, K., \& Zimmerman, E. (2004). Rules of Play. Game Design Fundamentals. Cambridge, MA; London, England: MIT Press.

Stein, L. E. (2017). Fandom and the Transtext. In B. W. L Derhy Kurtz \& M. Bourdaa (Eds.), The Rise of Transtexts. Challenges and Opportunities (pp. 71-89). Abingdon, England: Routledge. 
Thelosen, M. (Producer), \& Kaayk, F. (Director). (2016). The Modular Body [Online science fiction story]. Holand: seriousFilm, VPRO. Available in http://themodularbody.com/ 